\title{
Correction to: A time-driven activity-based costing approach for identifying variability in costs of childbirth between and within types of delivery
}

\author{
Kathia Dubron ${ }^{1^{*}}$ (D) Mathilde Verschaeve ${ }^{2}$ and Filip Roodhooft ${ }^{2,3}$
}

Correction to: BMC Pregnancy Childbirth 21, 705 (2021)

https://doi.org/10.1186/s12884-021-04134-4

Following publication of the original article [1], the authors reported an error in the response letter/peer review reports to the editors. The name of the hospital should be removed from the authors' response letter.

The original article [1] has been updated.

\section{Reference}

1. Dubron K, Verschaeve M, Roodhooft F. A time-driven activity-based costing approach for identifying variability in costs of childbirth between and within types of delivery. BMC Pregnancy Childbirth. 2021;21:705. https:// doi.org/10.1186/s12884-021-04134-4

\section{Author details}

${ }^{1}$ KU Leuven, University Hospital Leuven, Kapucijnenvoer 33, 3000 Leuven, Belgium. ${ }^{2} \mathrm{KU}$ Leuven, Faculty of Economics and Business, Research Centre Accountancy, Leuven, Belgium. ${ }^{3}$ Vlerick Business School, Accounting and Finance, Ghent, Belgium. 